\title{
DIALLEL ANALYSIS OF THE NUMBER OF GRAINS PER EAR IN SPRING BARLEY
}

\author{
T. J. RIGGS and A. M. HAYTER \\ Scottish Plant Breeding Station, Pentlandfield, Roslin, Midlothian
}

Received 1.ix.72

\begin{abstract}
SUMMARY
Diallel analysis was applied to untransformed data for number of grains per ear in spring barley. Heterogeneity of variances was detected when the 13-parent diallel containing 2-row and 6-row genotypes, was analysed. This heterogeneity was found to be much reduced when the two subsets, containing only 2-row and only 6-row genotypes, were analysed. Analyses of variance from 9-parent full diallels at $F_{1}$ for two seasons indicated significant differences between reciprocal crosses. Large and significant items for additive and nonadditive genetic variance were detected. Significant effects for additive and non-additive variation were also detected when data from 13-parent halfdiallels at $F_{1}$ and $F_{2}$ were analysed in both seasons. Graphical analysis of the 13-parent diallels revealed a high level of dominance with arrays of 2-row parents showing most dominance. Analysis of the 2-row populations revealed complete dominance acting in the direction of greater number of grains per ear. Tests for epistasis mostly failed to detect it but those interactions which did reach significance were generally of the duplicate type. Estimation of genetic components confirmed that a high level of dominance was operating in the inheritance of this character. Rather small effects for general and specific combining ability both for high and low numbers of grains per ear were detected, but significant positive correlations were found between the g.c.a. effects and the corresponding parental expression of the character. Significant interactions were detected between additive and non-additive effects at $F_{1}$ and years in analyses conducted over both seasons.
\end{abstract}

\section{INTRODUGTION}

Progress in the genetical analysis of yield in barley has been slow, as in the analysis of other complex characters, since in the early generations heritability estimates are generally low (Grafius, Nelson and Dirks, 1952). In view of this, several authors have stressed the importance of determining the nature and inheritance of the components of yield in barley and wheat rather than of yield itself (Whitehouse et al., 1958; Grafius, 1959; Whitehouse, 1968; Thomas et al., 1971a).

Perhaps the most comprehensive biometrical study of yielding capacity in barley yet attempted was that described by Johnson and Aksel (1959). Of the 15 parents used in a diallel cross, ten were 6-rowed and five 2-rowed. The authors concluded that the component " grains per ear " was predominant in determining yield under the conditions obtaining in the experiment and that high expression of this character was associated with an excess of recessive genes. This was found to be the case whether 2-rowed or 6 rowedmaterial was analysed. Hayes (1965) however, studying 2-rowed genotypes only, reported that dominance was acting in the direction of high number of grains per ear.

In the study to be reported here, this character was analysed in a 13- 
parent diallel grown in two seasons. Both 2-rowed and 6-rowed material was included.

\section{Materials and methods}

Details of the two main experiments from which the present data were obtained have been described elsewhere (Riggs and Hayter, 1972). Briefly, the experiments were arranged so that analysis could be conducted on a 9-parent full diallel set at $F_{1}$ and on 13-parent half diallel sets at $F_{1}$ and $F_{2}$. Two replicate blocks were grown in each of two seasons and plants were individually randomised at a spacing of $15 \mathrm{~cm}$. between rows and $7.5 \mathrm{~cm}$, between plants within rows.

The mean number of grains per ear was recorded for each plant by dividing the total number of grains recovered from the plant by the number of ears recorded at harvest.

A list of 13 parental varieties and the mean numbers of grains per ear in each season is given in table 1 .

TABLE 1

Number of grains per ear (means of 10 plants) for 13 parent varieties in each of two replicate blocks for two seasons

1970

$\begin{array}{ccc}\overbrace{\text { I }} & \text { II } & \text { Mean } \\ 26.33 & 26.22 & 26.28 \\ 29.90 & 33.40 & 31.65 \\ 17.22 & 15.20 & 16.21 \\ 16.30 & 16.10 & 16.20 \\ 18.50 & 19.50 & 19.00 \\ 26.10 & 28.70 & 27.40 \\ 24.37 & 31.57 & 27.97 \\ 17.00 & 16.67 & 16.84 \\ 16.40 & 19.00 & 17.70 \\ 20.10 & 20.10 & 20.10 \\ 15.22 & 17.00 & 16.11 \\ 13.60 & 15.11 & 14.36 \\ 18.00 \quad 16.20 & 17.10 \\ \underbrace{19.93}_{ \pm 1.61} & \pm 1.14 \\ \pm 0.45 & \end{array}$

* Indicates 6-row parents.

\begin{tabular}{lll}
$\overbrace{I}$ & II & Mean \\
44.20 & 33.10 & 38.65 \\
47.22 & 38.56 & 42.89 \\
20.44 & 19.20 & 19.82 \\
20.50 & 19.40 & 19.95 \\
22.50 & 24.10 & 23.30 \\
40.20 & 42.50 & 41.35 \\
38.50 & 40.43 & 39.47 \\
21.50 & 20.30 & 20.90 \\
21.40 & 19.00 & 20.20 \\
22.00 & 23.70 & 22.85 \\
21.00 & 18.40 & 19.70 \\
21.30 & 17.80 & 19.55 \\
23.40 & 21.33 & 22.37 \\
$\underbrace{28.01}_{\text {I2.01 }} 25.99$ & \pm 1.42 \\
\hline 0.56 &
\end{tabular}

\section{REsults}

Considerable heterogeneity of the within-family variances was detected in both seasons. The highest variances were associated with the 6-row parents and their crosses and when the 2-row and the 6-row populations were analysed separately the heterogeneity was found to be much reduced. Thus the high level of heterogeneity in the population as a whole was found to be largely a result of inherently different levels of variance associated with two sub-groups. This was not entirely the case, however, as heterogeneity of 
TABle 2

Analyses of variance for full diallels in each of two seasons

\begin{tabular}{|c|c|c|c|}
\hline Item & d.f. & $\begin{array}{c}9 \times 9 \text { F }_{1} 1970 \\
\text { M.S. }\end{array}$ & $\begin{array}{c}9 \times 9 F_{1} 1971 \\
\text { M.S. }\end{array}$ \\
\hline$a$ & 8 & $1248 \cdot 00 * * *$ & $3320 \cdot 56 * * *$ \\
\hline$b_{1}$ & 1 & $302 \cdot 04 * * *$ & $1001 \cdot 83 * * *$ \\
\hline$b_{2}$ & 8 & $40 \cdot 47$ & $223 \cdot 84^{* * *}$ \\
\hline$b_{3}$ & 27 & $351 \cdot 34 * * *$ & $454 \cdot 38 * * *$ \\
\hline$b$ & 36 & $280 \cdot 89 * * *$ & $418 \cdot 36 * * *$ \\
\hline$c$ & 8 & $84.52 * * *$ & $56 \cdot 02$ \\
\hline$d$ & 28 & $52 \cdot 50 * * *$ & $90 \cdot 68 * * *$ \\
\hline Blocks & 1 & $34 \cdot 36$ & $1700 \cdot 37 * * *$ \\
\hline$B a$ & 8 & $48 \cdot 08^{*}$ & $116 \cdot 07 * *$ \\
\hline$B b_{1}$ & 1 & $11 \cdot 22$ & $5 \cdot 65$ \\
\hline$B b_{2}$ & 8 & $22 \cdot 83$ & $125 \cdot 63 *$ \\
\hline$B b_{3}$ & 27 & $27 \cdot 60$ & $36 \cdot 64$ \\
\hline$B b$ & 36 & $26 \cdot 09$ & $55 \cdot 56$ \\
\hline$B c$ & 8 & $10 \cdot 40$ & $11 \cdot 70$ \\
\hline$B d$ & 28 & $16 \cdot 86$ & 56.53 \\
\hline$B t$ & 80 & 23.49 & $57 \cdot 56^{*}$ \\
\hline Within & & 22.02 (610 d.f.) & 43.46 (628 d.f.) \\
\hline
\end{tabular}

All effects tested against within-family variance.

variances was also detected in the sub-population consisting only of 2-row by 6 -row hybrids.

All analyses were conducted on untransformed data but the apparently non-random occurrence of widely differing variances will be discussed later.

\section{(i) Analysis of variance}

The analyses of variance (Hayman, 1954) are shown in tables 2 and 3 for the full and half diallel sets respectively. Highly significant additive and non-additive effects were indicated in all the analyses and evidence of reciprocal effects was detected in the full diallel sets in both seasons. Analyses for the 2-row population are shown in table 4 from which it will be noted that

TABLE 3

Analyses of variance for half diallels in each of two seasons for $F_{1}$ and $F_{2}$

\begin{tabular}{|c|c|c|c|c|c|}
\hline Item & d.f. & $\begin{array}{c}13 \times 13 F_{1} \\
1970 \\
\text { M.S. }\end{array}$ & $\begin{array}{c}13 \times 13 F_{1} \\
1971 \\
\text { M.S. }\end{array}$ & $\begin{array}{c}13 \times 13 F_{2} \\
1970 \\
\text { M.S. }\end{array}$ & $\begin{array}{c}13 \times 13 F_{8} \\
1971 \\
\text { M.S. }\end{array}$ \\
\hline$a$ & 12 & $939 \cdot 81 * * *$ & $3606 \cdot 75 * *$ & $1923 \cdot 01 * * *$ & $5046 \cdot 39 * * *$ \\
\hline$b_{1}$ & 1 & $386 \cdot 61 * * *$ & $1807 \cdot 60 * * *$ & 1.35 & $100 \cdot 41$ \\
\hline$b_{\mathrm{a}}$ & 12 & $135 \cdot 76^{* * *}$ & $632.59 * * *$ & $55 \cdot 22 * * *$ & $223.65 * * *$ \\
\hline$b_{3}$ & 65 & $217 \cdot 81 * * *$ & $271 \cdot 11 * * *$ & $114.59 * * *$ & $130 \cdot 12 * * *$ \\
\hline$b$ & 78 & $207 \cdot 35^{* * *}$ & $346 \cdot 42 * * *$ & $104 \cdot 00 * * *$ & $144 \cdot 13 * * *$ \\
\hline Blocks & 1 & 0.01 & $2090 \cdot 52 * * *$ & 0.43 & $1558.02 * * *$ \\
\hline$B a$ & 12 & $40.90 * *$ & $90 \cdot 75 *$ & $36 \cdot 85^{*}$ & $166.98 * * *$ \\
\hline$B b_{1}$ & 1 & $109 \cdot 90^{*}$ & 1.03 & $105 \cdot 27 *$ & $2 \cdot 36$ \\
\hline$B b_{2}$ & 12 & $35 \cdot 15^{*}$ & $50 \cdot 68$ & $32 \cdot 67^{*}$ & $68 \cdot 74 *$ \\
\hline$B b_{3}$ & 65 & $20 \cdot 16$ & 29.97 & $48 \cdot 27 * * *$ & $107 \cdot 19 * * *$ \\
\hline$B b$ & 78 & $23 \cdot 62$ & $32 \cdot 79$ & $46 \cdot 60 * * *$ & $99.93 * * *$ \\
\hline Bt & 90 & $25.92 * *$ & 40.51 & $45 \cdot 30 * * *$ & $108 \cdot 87 * * *$ \\
\hline Within & $\begin{array}{l}\text { variance } \\
\text { nts) }\end{array}$ & 17.19 (1566 d.f.) & 34.21 (1608 d.f.) & & \\
\hline
\end{tabular}

All effects tested against within-family variance.

$31 / 1-G$ 
the non-additive component of the variance was contained almost entirely in the $b_{1}$ item.

\section{(ii) Graphical analysis}

Regressions of $W r$ on $V r$ for the full diallel and the half diallel sets at $\mathrm{F}_{1}$ gave coefficients close to unity with the points representing arrays of 6-row parents forming a cluster with high values of $V r$ and $W r$, far removed from the cluster representing arrays of 2-row parents, which was close to the origin. By plotting standardised values of $y r$, the parental mean, against $W r+V r$, an inverse measure of dominance, it was clearly demonstrated that dominance was acting in the direction of low numbers of grains per ear, corresponding to 2-row $v$. 6-row expression.

After correcting $\overline{W r}$ and $\overline{V r}$ for their environmental components, $\overline{W r}-\overline{\nabla r}$ was found to be $-2 \cdot 812 \pm 0.549$ and $2.435 \pm 1.003$ for the 1970 and 1971 data

TABLE 4

Analyses of variance for half diallels in each of two seasons for 2-row genotypes at $F_{1}$ and $F_{2}$

\begin{tabular}{|c|c|c|c|c|c|}
\hline Item & d.f. & $\begin{array}{c}\text { 2-row F } \\
1970 \\
\text { M.S. }\end{array}$ & $\begin{array}{c}\text { 2-row } \mathrm{F}_{1} \\
1971 \\
\text { M.S. }\end{array}$ & $\begin{array}{c}\text { 2-row } \mathrm{F}_{2} \\
1970 \\
\text { M.S. }\end{array}$ & $\begin{array}{c}\text { 2-row } F_{8} \\
1971 \\
\text { M.S. }\end{array}$ \\
\hline$a$ & 8 & $9 \cdot 86^{* * *}$ & $12 \cdot 10^{* * *}$ & $10.54 * * *$ & $7 \cdot 63 * * *$ \\
\hline$b_{1}$ & 1 & $43 \cdot 67 * * *$ & $33 \cdot 60^{* * *}$ & $18 \cdot 36 * *$ & 26.00 *** \\
\hline$b_{2}$ & 8 & 0.60 & $1 \cdot 18$ & 1.66 & 1.89 \\
\hline$b_{8}$ & 27 & 1.41 & $1.99 *$ & $2 \cdot 57$ & $1 \cdot 11$ \\
\hline$b$ & 36 & $2 \cdot 41$ & $2 \cdot 69 * *$ & $2 \cdot 81$ & 1.98 \\
\hline Blocks & 1 & $3 \cdot 29$ & $29 \cdot 19 * * *$ & $4 \cdot 67$ & $11 \cdot 33^{*}$ \\
\hline$B a$ & 8 & 0.85 & 0.55 & 0.87 & 0.50 \\
\hline$B b_{1}$ & 1 & $2 \cdot 48$ & 0.02 & 3.06 & 1.36 \\
\hline$B b_{\mathrm{g}}$ & 8 & 1.38 & 1.87 & $1 \cdot 14$ & 2.01 \\
\hline$B b_{8}$ & 27 & 1.90 & 1.00 & $2 \cdot 24$ & 1.82 \\
\hline$B b$ & 36 & 1.80 & $1 \cdot 16$ & 2.02 & 1.84 \\
\hline$B t$ & 44 & 1.59 & 1.03 & 1.77 & 1.57 \\
\hline
\end{tabular}

All effects tested against $B t$.

respectively (Mather and Jinks, 1971). Over-dominance was therefore apparent in the 1970 data whereas in 1971 dominance was incomplete.

At $\mathrm{F}_{2}$, with dominance halved, the regressions were more easily plotted and the graph for the half diallel in 1971 is shown in fig. 1 . The extreme recessive positions for the arrays for 6-row parents were still evident and, of the 2-row arrays, the point for Cambrinus (3) occupied the extreme dominant position in both seasons. The correlations between $y r$ and $W r+V r$ were high and positive $(r=0.9320, \mathrm{P}<0.001$, and $r=0.8249, \mathrm{P}<0.001$ for the 1970 and 1971 seasons respectively), confirming that dominance was acting in the direction of low expression of the character.

Considering 2-row genotypes only, $W / V$ analyses were inconsistent. The data for replicate block $I$ in 1970 gave a regression coefficient close to unity whilst that in block II was not significantly different from zero. The 1971 data gave non-significant regression coefficients for both replicate blocks. After correcting $W_{r}$ and $\nabla_{r}$ for their environmental components, $D$ was shown to be equal to $H_{1}$ by $W_{r} / V_{r} \bumpeq 1$ (Jinks, 1954) except for block I in 1971, and it will be shown later that gene frequencies were approximately equal, at least in the 1970 experiment, over all loci. The failure of the $W / V$ test for 
the 2-row genotypes at $F_{1}$ must therefore be attributed to gene interaction. At $F_{2}$ regressions of $W r$ on $V r$ again showed departures from a slope of 1 .

The relationship between parental expression and degree of dominance for the $F_{1}$ generation was best shown by plotting standardised values for $y r$ and $W r+\operatorname{Vr}$ (fig. 2). The graphs for the two seasons were similar particularly with respect to arrays, 5, 8, 10 and 13 .

Correlations between $y r$ and $W r+V r$ for $\mathrm{F}_{2}$ data were negative in both seasons $(r=-0.8034, \mathrm{P}<0.01$, and $r=-0.6792, \mathrm{P}<0.05$ respectively).

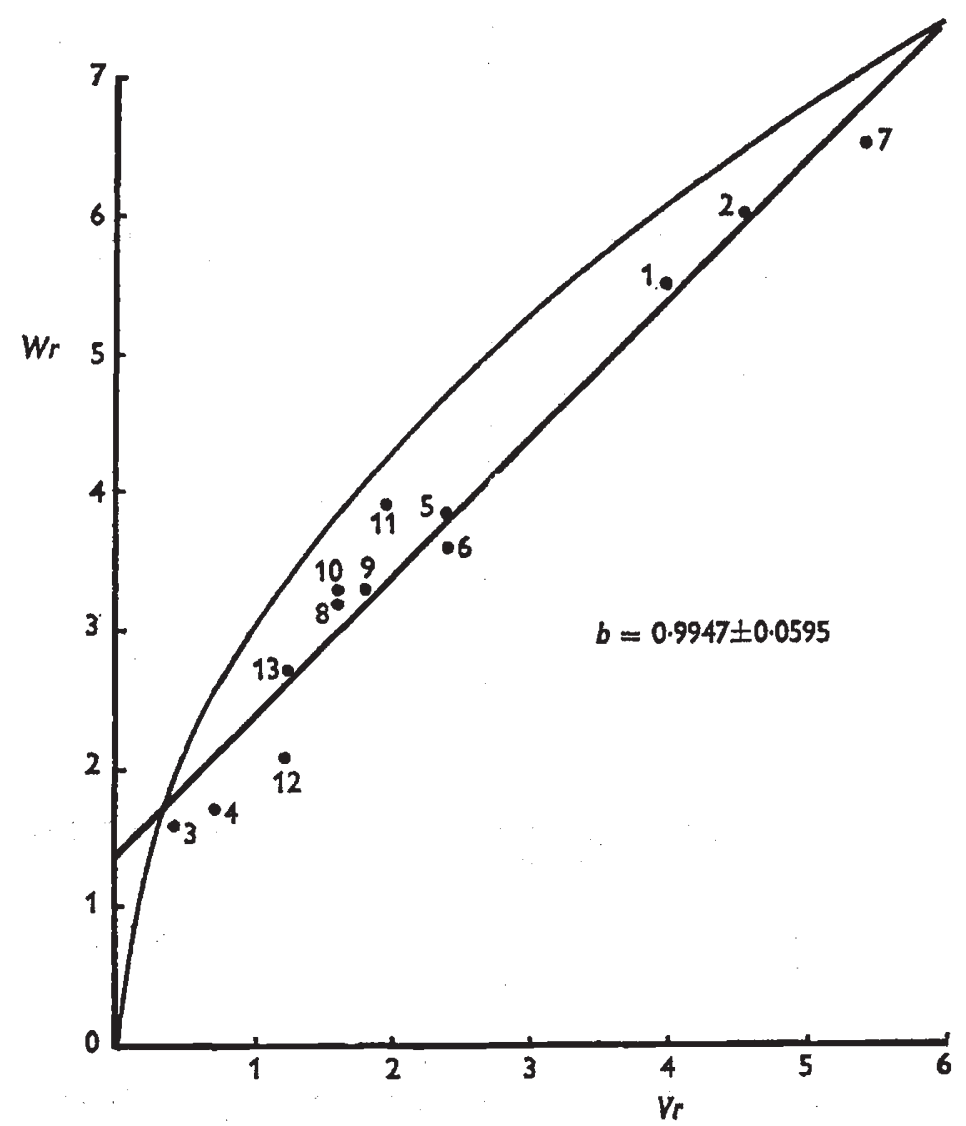

FIG. 1.-W/V graph, $F_{2}$ data for 1971 , means over replicate blocks.

Within the 2-row genotypes dominance was thus found to be acting in the direction of greater numbers of grains.

\section{(iii) Epistasis}

The analysis for epistasis described by Hayman (1957) was performed on the $9 \times 9$ half diallel involving only 2-row parents. Chi-squared tests for epistasis were not significant, with the exception of that for one replicate block in the 1970 season $(\mathrm{P}<0.05)$. When the $\mathrm{C}$-scaling test was performed on the $13 \times 13$ half diallel, significant interactions were detected though no one array showed conspicuously more interacting crosses than any of the others and interactions were not generally consistent between blocks. Of 


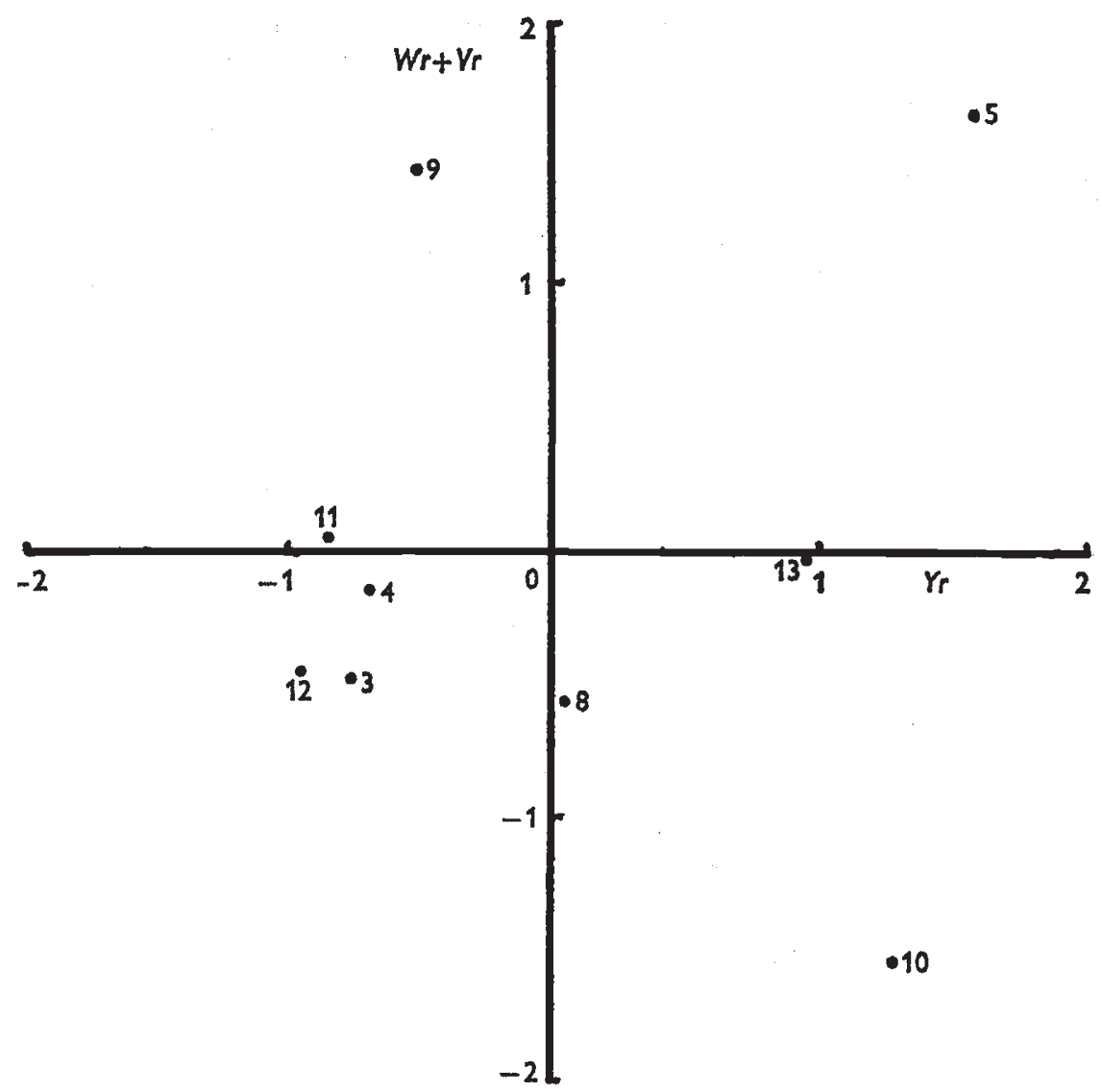

Fic. 2.-Standardised deviation for $y r$ and $W r+V r$. 2-row genotypes only, $\mathbf{F}_{1}$ data for 1971 , means over replicate blocks.

the interacting crosses most were of the duplicate type though in general the degree of epistasis detected was slight.

\section{(iv) Components of variation}

For the estimation of the seven components of variation, 12 statistics were available from the pooled $F_{1}$ and $F_{2}$ data. An unweighted least squares analysis was performed (Mather, 1949; Mather and Vines, 1952; Mather and Jinks, 1971) and the components, with their standard errors, are given in table 5 .

Considering the results from the 13-parent diallel sets in 1970 and 1971 (table 5), the existence of high dominance indicated by the graphical analysis was confirmed by $\left(H_{1} / D\right) \bumpeq 1$. The values of $H_{1}$ and $H_{2}$ in the 1970 experiment were very similar, indicating equal gene frequencies, but the 1971 results showed $H_{1}$ as somewhat larger than $H_{2}$. In addition, the large positive value of $F$ further suggests inequality of gene frequencies with an excess of dominant over recessive alleles. The ratio of $h$ to $d$ as measured by the quantity, $\frac{7}{2} F / \sqrt{\left(D\left(H_{1}-H_{2}\right)\right)}$ in 1971 , was apparently constant.

Very similar conclusions could be drawn from the components estimated 
for the population of 2-row genotypes. In the absence of the 2-row $v$. 6-row comparison, which might have accounted for all the dominance measured in the 13-parent diallel set, considerable dominance was again demonstrated, confirming results in table 4. Again, approximately equal gene frequencies were indicated by $H_{2} / 4 H_{1} \bumpeq 0.25$ in the 1970 experiment.

The values for the seven components were used to reconstruct values for the statistics and the overall deviation of observed from expected was tested against heterogeneity between blocks (Mather and Jinks, 1971). In the case of the 13-parent diallel sets in 1970 and 1971 the overall deviation item was found to be significant. This indicates a failure of the model due to epistasis. The goodness of fit of the model was similarly tested for the components derived from the population composed of 2-row genotypes only and in this case the overall deviation was not significantly greater than the heterogeneity among the parts of the experiments. Such a result does not necessarily, however, indicate that the fit of the model is good, but merely

TABle 5

Components of variation for grains per ear in two seasons. $13 \times 13$ half diallel, $F_{1}$ and $F_{2}$

\begin{tabular}{|c|c|c|c|c|}
\hline \multirow[b]{2}{*}{ Component } & \multicolumn{2}{|c|}{$\begin{array}{l}1970 \\
\text { Blocks }\end{array}$} & \multicolumn{2}{|c|}{$\begin{array}{c}1971 \\
\text { Blocks }\end{array}$} \\
\hline & I & II & I & II \\
\hline $\begin{array}{l}D \\
H_{1} \\
H_{2} \\
F \\
E_{0} \\
E_{1} \\
E_{9} \\
\left(H_{1} / D\right)^{+} \\
H_{2} / 4 H_{1}\end{array}$ & $\begin{array}{c}24.79 \pm 2 \cdot 40 \\
21 \cdot 22 \pm 9 \cdot 67 \\
23.59 \pm 9 \cdot 46 \\
14.76 \pm 6.48 \\
1.96 \pm 1 \cdot 70 \\
1.87 \pm 1 \cdot 57 \\
4 \cdot 19 \pm 1 \cdot 28 \\
0.92 \\
0.28\end{array}$ & $\begin{array}{c}40.96 \pm 2.75 \\
41.48 \pm 11.07 \\
43.20 \pm 10.84 \\
26.01 \pm 7.43 \\
1.56 \pm 1.95 \\
2.49 \pm 1.80 \\
5.84 \pm 1.49 \\
1.01 \\
0.26\end{array}$ & $\begin{array}{c}101.58 \pm 5.52 \\
54.92 \pm 22.26 \\
46.21 \pm 21.79 \\
60.83 \pm 14.93 \\
4.28 \pm 3.91 \\
4.75 \pm 3.61 \\
9.56 \pm 2.95 \\
0.73 \\
0.21\end{array}$ & $\begin{array}{c}80 \cdot 69 \pm 4 \cdot 09 \\
58 \cdot 18 \pm 16 \cdot 48 \\
47 \cdot 69 \pm 16 \cdot 13 \\
51 \cdot 39 \pm 11 \cdot 05 \\
3 \cdot 98 \pm 2 \cdot 90 \\
3 \cdot 60 \pm 2 \cdot 67 \\
9 \cdot 21 \pm 2 \cdot 18 \\
0 \cdot 85 \\
0 \cdot 20\end{array}$ \\
\hline $\begin{array}{l}\frac{1}{F} / \sqrt{\left[D\left(H_{1}-H_{2}\right)\right]} \\
\left(4 D H_{1}\right)^{1}+F /\left(4 D H_{1}\right)^{t}-F\end{array}$ & 1.95 & 1.92 & $\begin{array}{l}1 \cdot 02 \\
2 \cdot 37\end{array}$ & $\begin{array}{l}0.88 \\
2 \cdot 20\end{array}$ \\
\hline
\end{tabular}

that at the level of accuracy of the experiments the model cannot be shown to be inappropriate.

\section{(v) General and specific combining ability}

The data for the 2-row genotypes in each block were analysed for each season using the Method 4, Model I analysis of Griffing (1956). The analyses of variance revealed significant items for g.c.a. and s.c.a. in both seasons, but the combining ability effects were rather small (tables 6 and 7).

Little consistency was apparent in the sign of s.c.a. effects between seasons or between blocks. G.c.a. effects were more consistent however: Cambrinus (3), Mosane (11) and Sultan (12) exhibited negative effects in both seasons, whilst Midas (10) exhibited relatively high positive effects. With one exception, significant positive correlations were detected between the g.c.a. effects and the corresponding parent expression of the character (table 1 ).

(vi) Analysis over seasons

Analyses of variance on data from both seasons showed, as expected, highly significant differences associated with years. In addition the analyses 
of the $\mathrm{F}_{1}$ data showed significant additive and non-additive effects $x$ years interaction.

\section{Discussion}

Although a clear confirmation of the dominance of the 2-row expression, in hybrids between 2-row and 6-row parents, was demonstrated there appeared to be marked differences in the levels of variation within the 2-row and the 6-row populations. Relatively high variances within the 6-row population were not entirely unexpected since some of the 6-row material was found to be prone to shattering of the ear which led to some losses during harvest. Wherever possible, the loss of part of a spike was taken into account but some inflation of the variance was probably inevitable.

The same explanation might be given for the heterogeneity of variance within the 2-row by 6-row hybrid population, since the hybrids, whilst having 2-row spikes may have inherited the brittleness of the rachis associated with some of the 6-row parents. The possibility of a genetic explanation cannot be ruled out since analysis of the coefficients of variation, computed for each family, indicated significant additive and non-additive components of variation. Brittleness might be associated with earliness in the sense that the early genotypes would be "over-ripe ", and thus prone to shattering, by the time the trial was harvested. The 6-row genotypes were earlier, in terms of days to heading, than the 2-row genotypes and exhibited dominance for this character (Riggs and Hayter, 1972).

In an analysis of the components of yield in a 4-parent diallel cross in wheat, Whitehouse et al. (1958) concluded that all the components were under predominantly additive control. When the same data were transformed (Thomas et al., $1971 a, b$ ) so as to remove the correlations between the traits, deviations from additive control were detected with dominance and/or genic interaction increasing with each component in sequential order.

Our own untransformed data have exhibited a high level of non-additive genetic variation and the 2-row population showed significant $b_{1}$ items in the analyses of variance (table 4). This item tests the mean deviation of the $\mathrm{F}_{1}$ 's from the mid-parental values, and the hybrids exceeded the mid-parents by an average of 10.5 per cent. in 1970 and 7.4 per cent. in 1971. However, comparison of each hybrid with the parent giving the highest expression of the character showed an average increase, associated with the hybrids, of 4.0 per cent. in 1970 , the poorer of the two seasons, and 1.6 per cent. in 1971 . Heterosis in this sense may be regarded as negligible.

The order of dominance, acting in the direction of low numbers of grains per ear, detected in the complete data supported the results of Johnson and Aksel (1959), but when 2-row genotypes only were analysed at $F_{2}$ dominance was found to be acting towards increased expression of the character. These findings agree with those of Hayes (1965) but not with those of Johnson and Aksel (1959).

Aksel and Johnson (1961) studied the relation between maturity periods and yield and its components. They found that varieties with longer sowingto-heading period tended to have higher numbers of grains per ear and to produce higher yields. In our results no clear correlation could be found between parental measurements for grains per ear and for the number of days to ear emergence in the 2-row population. The varieties Midas, 


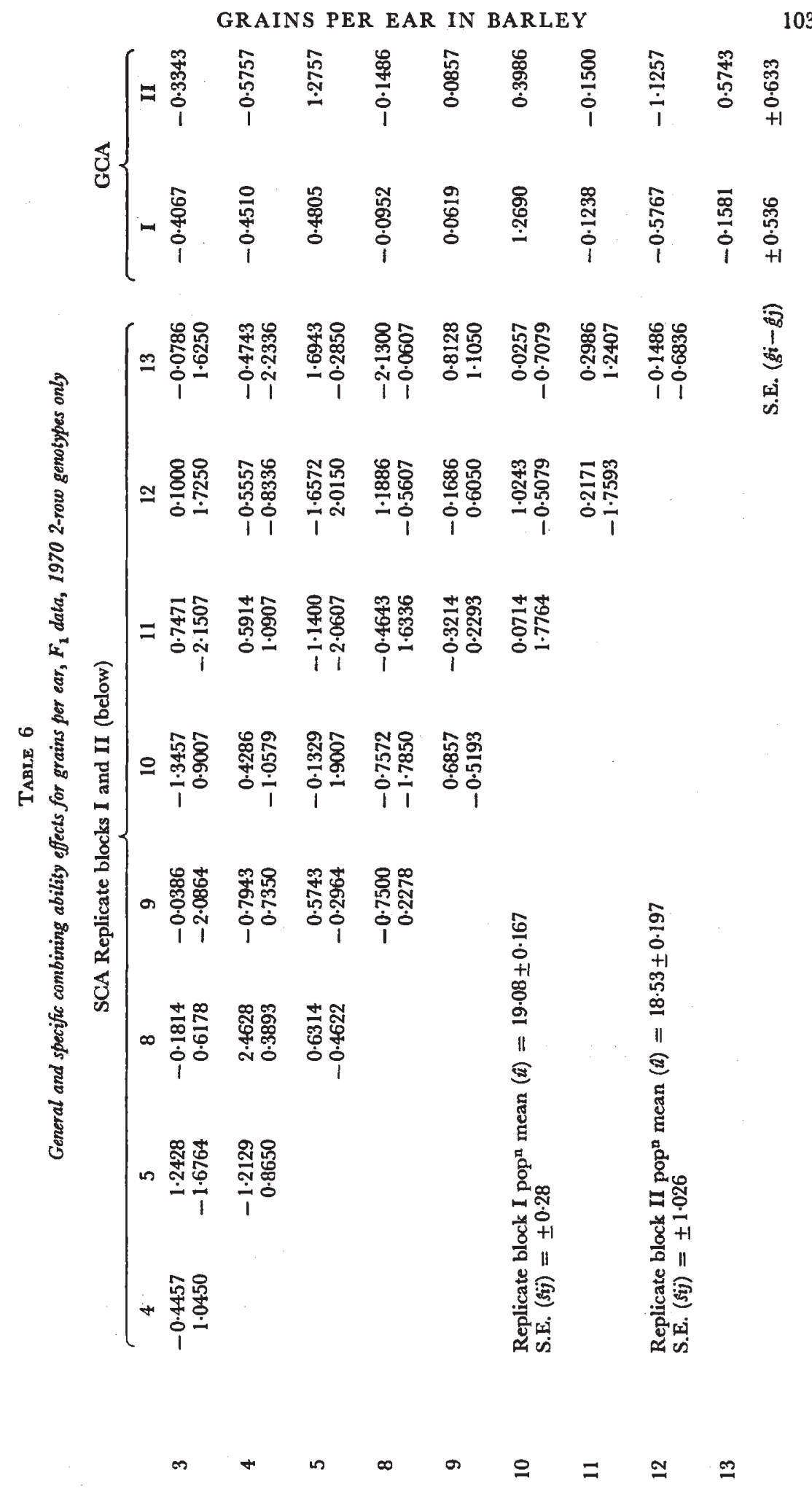


T. J. RIGGS AND A. M. HAYTER

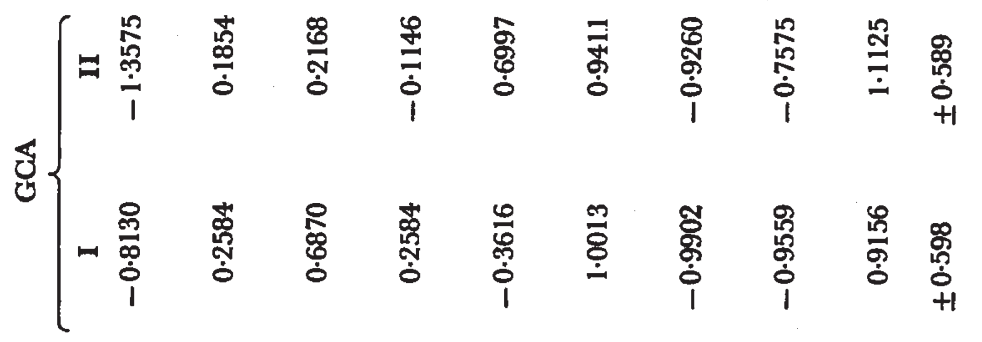

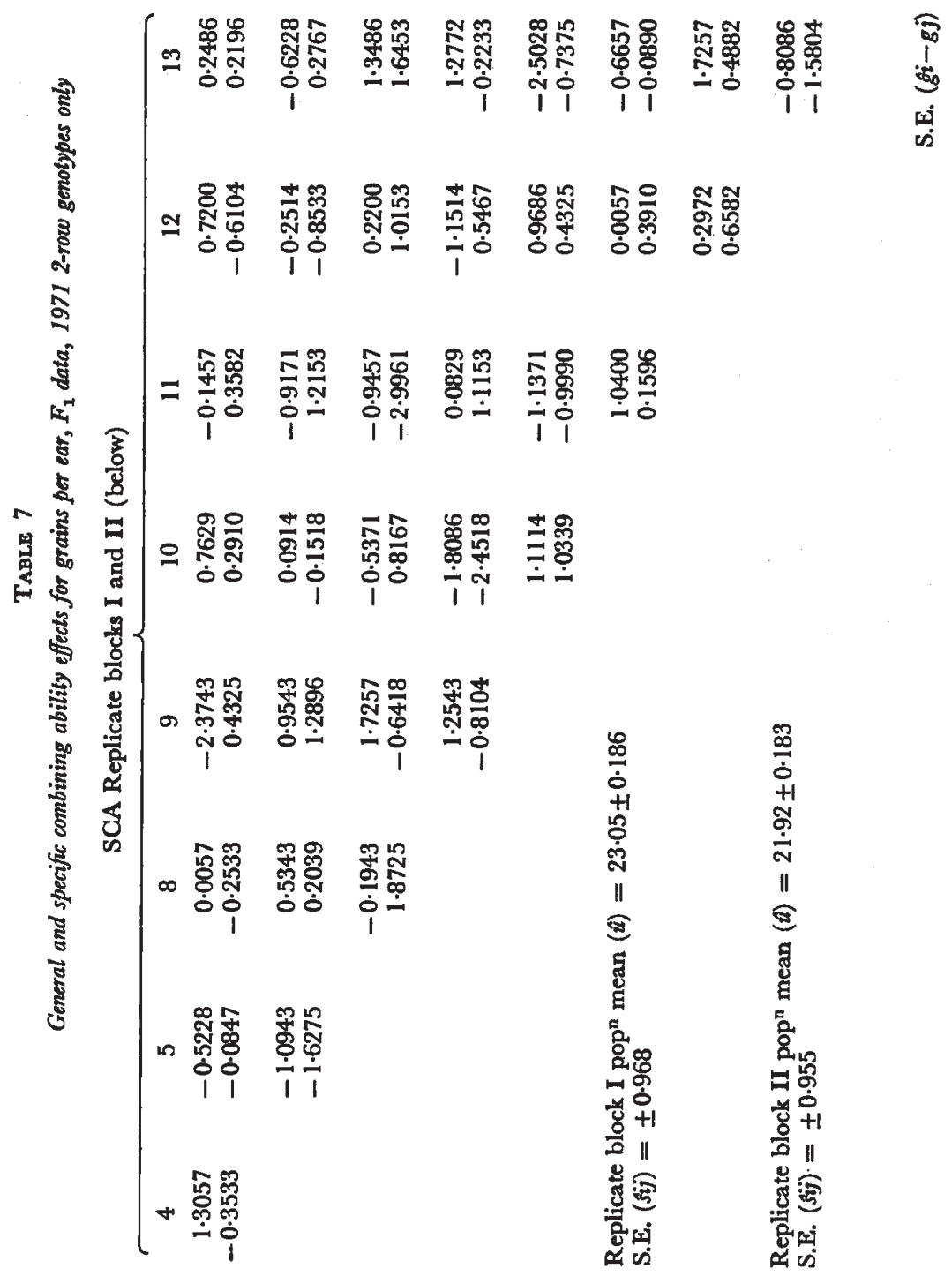

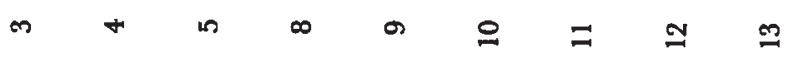


Boreham Warrior and Deba Abed showed high expression of the character grains per ear and although Boreham Warrior and Midas were late, under our conditions, for the number of days to ear emergence, Deba Abed was a relatively early variety (Riggs and Hayter, 1972). In addition Sultan, which was ranked low for grains per ear was only 2-3 days earlier than Boreham Warrior, the latest parent. The correlation coefficients were $r=0.0733$ for 1970 and $r=0.3830$ for 1971 .

The implications for the plant breeder of these results can only be fully assessed when analysis of the remaining yield components is complete, but the detection of large additive effects in the inheritance of this character suggests that no difficulty should be experienced by the breeder in attempting to fix the desired expression. The demonstration of interaction between additive effects and seasons implies, however, that general combining ability effects estimated in one season only may be an inadequate basis for decision making. The detection of a positive correlation between g.c.a. effect and parent expression suggests a further aid in the choice of parents.

\section{ReFERENGES}

AKsel, R., AND JOHNSON, L. P. v. 1961. Genetic studies on sowing-to-heading and headingto-ripening periods in barley and their relation to yield and yield components. Can. $\mathcal{J}$. Genet. Cytol., 3, 242-259.

Grafius, J. E. 1959. Heterosis in barley. Agron. 7., 51, 551-554.

GRAFIUS, J. E., NELSON, W. L., AND DIRKs, v. A. 1952. The heritability of yield in barley as measured by early generation bulked progenies. Agron. 7., 44, 253-257.

GRIFFING, J. B. 1956. Concept of general and specific combining ability in relation to diallel crossing systems. Austral. F. Biol. Sc., 9, 463-493.

HAYES, J. D. 1965. A study of early generation assessment in cereals, with particular reference to barley. Ph.D. thesis, Univ. Wales.

HAYMAN, B. 1. 1954. The analysis of variance of diallel tables. Biometrics, 10, 235-244.

hayman, B. 1. 1957. Interaction, heterosis and diallel crosses. Genetics, 42, 336-355.

JnNks, J. L. 1954. The analysis of continuous variation in a diallel cross of Nicotiana rustica varieties. Genetics, 39, 767-788.

JOHNSON, L. P. V., AND AKSEL, R. 1959. Inheritance of yielding capacity in a fifteen-parent diallel cross of barley. Can. J. Genet. Cytol., 1, 208-265.

MATHER, K. 1949. Biometrical Genetics. Methuen \& Co., London.

MATHER, K., AND JINks, J. L. 1971. Biometrical Genetics. Chapman and Hall, London.

MATHER, K., AND vINEs, A. 1952. The inheritance of height and flowering time in a cross of Nicotiana ructica. Quantitative Inheritance, ed. E. C. R. Reeve and C. H. Waddington, pp. 49-80. H.M.S.O. London.

NILAN, R. A. 1964. The cytology and genetics of barley 1951-1962. Monographic Suppl. No. 3. Research Studies. Washington State University.

RIGGS, T. J., AND HAYTER, A. M. 1972. Diallel analysis of the time to heading in spring barley. Heredity, 29, 341-357.

THOMAS, R. L., GRAFIUS, J. E., AND HAHN, s. K. 197la. Genetic analysis of correlated sequential characters. Heredity, 26, 177-188.

THOMAS, R. L., GRAFIUS, J. E., AND HAHN, s. K. 1971b. Transformation of sequential quantitative characters. Heredity, 26, 189-193.

whrtehouse, R. N. H. 1968. Barley Breeding at Cambridge. Rep. Pl. Breed. Inst., Cambridge, 1968, pp. 6-29.

WHItEhouse, R. N. H., THOMPSON, J. B., AND RIBEIRO, M. A. M. DE V. 1958. Studies on the breeding of self-pollinated cereals. 2. The use of a diallel cross analysis in yield prediction. Euphytica, 7, 147-169. 